\title{
Local ablation or radioembolization of colorectal cancer metastases: comorbidities or older age do not affect overall survival
}

Ricarda Seidensticker ${ }^{1,6 \dagger}{ }^{2}$, Robert Damm ${ }^{2 *}{ }^{*}$, Julia Enge ${ }^{2}$, Max Seidensticker ${ }^{1,6}$, Konrad Mohnike ${ }^{3,6}$, Maciej Pech ${ }^{2,6}$, Peter Hass ${ }^{4}$, Holger Amthauer ${ }^{5,6}$ and Jens Ricke ${ }^{1,6}$

\begin{abstract}
Background: Local ablative techniques are emerging in patients with oligometastatic disease from colorectal carcinoma, commonly described as less invasive than surgical methods. This single arm cohort seeks to determine whether such methods are suitable in patients with comorbidities or higher age.

Methods: Two hundred sixty-six patients received radiofrequency ablation (RFA), CT-guided high-dose rate brachytherapy (HDR-BT) or Y90-radioembolization (Y90-RE) during treatment of metastatic colorectal cancer (mCRC). This cohort comprised of patients with heterogenous disease stages from single liver lesions to multiple organ systems involvement commonly following multiple chemotherapy lines. Data was reviewed retrospectively for patient demographics, previous therapies, initial or disease stages at first intervention, comorbidities and mortality. Comorbidity was measured using the Charlson Comorbidity Index (CCl) and age-adjusted Charlson Index (CACl) excluding $\mathrm{mCRC}$ as the index disease. Kaplan-Meier survival analysis and Cox regression were used for statistical analysis.
\end{abstract}

Results: Overall median survival of 266 patients was 14 months. Age $\geq 70$ years did not influence survival after local therapies. Similarly, $\mathrm{CCl}$ or $\mathrm{CACl}$ did not affect the patients prognoses in multivariate analyses. Moderate or severe renal insufficiency $(n=12 ; p=0.005)$ was the only single comorbidity identified to negatively affect the outcome after local therapy.

Conclusion: Interventional procedures for mCRC may be performed safely even in elderly and comorbid patients. In severe renal insufficiency, the use of invasive techniques should be limited to selected cases.

Keywords: Colorectal cancer, Elderly patients, Comorbidities, Multimodal therapy

\section{Background}

Age is a major risk factor for colorectal cancer (CRC) and cancer in general [1]. Elderly patients often suffer from comorbidity and reduced organ function thus requiring particular considerations when making treatment decisions. Additionally elderly patients present a very heterogeneous group with chronological age being insufficient to describe individual resources and deficits. Contributing to these difficulties in decision making,

\footnotetext{
* Correspondence: Robert.Damm@med.ovgu.de

${ }^{\dagger}$ Ricarda Seidensticker and Robert Damm contributed equally to this work.

2Department of Radiology and Nuclear Medicine,

Otto-von-Guericke-University Magdeburg, Leipziger Str. 44, 39120

Magdeburg, Germany

Full list of author information is available at the end of the article
}

elderly patients are underrepresented in cancer trials while they account for most of the actual patients [2]: When analyzing $495 \mathrm{NCI}$ (National Cancer Institute) studies, Lewis et al. found that only $32 \%$ of cancer trial participants were age 65 years and older, in contrast to $61 \%$ in the US cancer population [3]. Other authors have published similar results, with an even greater difference for patients aged 70 years and older [4]. Although there is evidence that age should not be a reason to refrain from surgery and chemotherapy, most studies comprise a higher age and comorbidities as exclusion criteria [5-7]. In clinical practice, patients at higher age or with comorbidities often receive the recommended chemotherapies at reduced doses outside

(c) The Author(s). 2018 Open Access This article is distributed under the terms of the Creative Commons Attribution 4.0 International License (http://creativecommons.org/licenses/by/4.0/), which permits unrestricted use, distribution, and reproduction in any medium, provided you give appropriate credit to the original author(s) and the source, provide a link to the Creative Commons license, and indicate if changes were made. The Creative Commons Public Domain Dedication waiver (http://creativecommons.org/publicdomain/zero/1.0/) applies to the data made available in this article, unless otherwise stated. 
the standard prescription [8-10]. Yet, the effectiveness of such adapted therapy regimen is unknown.

Local ablative treatments (LAT, e.g. radiofrequency/ microwave ablation and interstitial HDR-brachytherapy) as well as locoregional therapies (e.g. Y90 radioembolization) offer local tumor control and extensive cytoreduction with low morbidity and mortality. In oligometastatic disease with few tumor sites and limited number of metastases, LAT can achieve long-term disease control by complete tumor ablation in patients not eligible for surgery [11]. In contrast, locoregional therapies such as Y90 radioembolization may contribute to the overall survival of selected patient by improving the local response in liver-dominant disease or by providing a salvage treatment in chemo-refractory liver metastases [12, 13]. Accordingly, the toolbox of local ablative treatments and locoregional therapies was included in the latest ESMO guideline for colorectal cancer with oligometastatic disease or liver dominant, chemo-refractory metastases [14]. In the context of elderly and comorbid patients, data on the efficacy of LAT is still rare.

This study aims to assess the influence or absence of negative effects of higher age or comorbiditieson the outcome after local therapies. We hypothesize that minimal-invasive local or locoregional techniques add further value by offering broader treatment options in elderly and comorbid patients with metastatic colorectal disease.

\section{Methods}

\section{Patient cohort}

We searched our institutional data base for all patients with $\mathrm{mCRC}$ receiving at least one radiofrequency ablation (RFA), high-dose-rate brachytherapy (HDR-BT) or Y90-radioembolization (Y90-RE) between 2006 and 2010. We included all patients with complete records on patient history and at least one follow up visit.

The study comprised a total of 266 patients (179 male, 87 female; mean age 66 years). One hundred ninety-six patients (73.7\%) had synchronous metastases within 12 months after diagnosis of the primary tumor. Nearly all patients presented with hepatic metastases $(n=251,94.4 \%)$. Further sites of dissemination included lung $(n=77,28.4 \%)$, lymphatic $(n=44,16.5 \%)$, osseous $(n=10,3.8 \%)$ or other metastases $(n=22,8.3 \%)$. Most of the patients failed at least one $(n=79,29.7 \%)$ or two $(n=160,60.2 \%)$ lines of chemotherapy compromising either irinotecan or oxaliplatin combined with 5-fluorouracil. Additionally, 169 patients (63.5\%) received EGFR or VEGF inhibiting therapy. Prior surgical treatments included surgery for the primary tumor in 263 patients $(98.9 \%)$, resection of hepatic metastases in 91 patients (34.2\%) and resection of lung/other metastases in 34 patients (12.8\%).
Throughout the observation period, nearly half of the patients developed further liver metastases $(n=118$, 44.4\%) followed by lung metastases ( $n=108,40.6 \%)$, lymphatic metastases $(n=51,19.2 \%)$, osseous metastases $(n=18,6.8 \%)$ and other $(n=73,27.4 \%)$.

Patients were considered for local ablative treatment and $\mathrm{Y} 90$ radioembolization by a multidisciplinary team (MDT; including medical, surgical and radiation oncologists) depending on their stage of disease (e.g. size of tumor, number of lesions, tumor sites) as well as organ function and performance status. Local ablation was selected in potentially resectable metastases only if patients had an unfavorable performance status and/ or severe comorbidities (resulting in a high risk of perioperative morbidity and mortality) or if patients refused surgery. Patients with single lesions up to $3 \mathrm{~cm}$ in diameter were preferably treated by radiofrequency ablation. If the localization and number of metastases or tumor size above $3 \mathrm{~cm}$ limited RFA, interstitial HDR brachytherapy was applied for oligometastatic disease. Patients with diffuse, liver-dominant involvement underwent Y90 radioembolization. In case of tumor progress during follow-up, patients were reassessed by the MDT for the next treatment step, i.e. further local treatment strategies and/or systemic therapy. In total, 732 interventions were performed.

\section{Local and locoregional therapies}

The following image guided techniques were considered by the MDT (if not eligible for systemic therapy only).

\section{Radiofrequency ablation}

Radiofrequency ablation induces a coagulation necrosis of tumor tissue by generating heat [15]. RFA is considered to be a safe and effective method with major complications occurring in $1-5 \%$ of patients. Beside limitations according to proximity to vulnerable organs, RFA underlies a heat-sink effect restricting the maximum size of the coagulation necrosis [16].

In our study, local ablation for smaller lung or liver metastases $(<3 \mathrm{~cm})$ was performed using CT-guided radiofrequency ablation (LeVeen ${ }^{\circ}$, Boston Scientific, Natrick, United States or Starburst Semi-Flex, AngioDynamics, Mountain View, Canada) according to manufacturer's specifications. A total of 21 liver and 77 lung RFA interventions were conducted.

\section{CT guided high-dose rate brachytherapy}

CT-guided HDR-BT is an ablative technique utilizing radiation from an Iridium-192 source in afterloading technique. Interstitial catheters were inserted by CT-guidance and subsequent 3D treatment planning was applied (Oncentra ${ }^{\circ}$, Nucletron, Veenendaal, The Netherlands). As the catheters are fixed within the tumor, the delivery of 
irradiation is not affected by breathing motion. As a consequence, dose delivery to the tumor is highly accurate and exposure of healthy tissues or risk organs can be reduced to a minimum [17].

Since HDR-BT has no systematic restrictions for tumor size and location close to vessels, it was preferably indicated if multiple tumors were present as well as in larger $(>3 \mathrm{~cm})$ liver or lung metastases or any lymphatic metastases [18-20]. To ensure a complete ablation, a target dose of 20Gy in a single session was subscribed [21]. HDR-BT was mainly used for liver ablations $(n=422)$, as well as for ablation of lung metastases $(n=52)$, lymphatic nodes $(n=9)$ and other tumor sites $(n=8)$.

\section{Y90-radioembolization}

If number, size or location of liver metastases exceeded the capabilities of local ablation by RFA or HDR-BT, patients were subsequently evaluated for loco-regional radioembolization using microspheres labeled with the beta-emitter Yttrium-90 (half-life $64 \mathrm{~h}$; mean energy $0.96 \mathrm{MeV}$ ) administered through an angiographic catheter to the liver arteries [22, 23]. Multinodular liver metastases were treated in 96 cases by 142 radioembolizations using Y90 resin microspheres (SIR-Spheres ${ }^{\circ}$, Sirtex Medical, Lane Cove, Australia), the required dose was calculated previously according to the bodysurface area method after an initial evaluation with Technecium-99 m macro-aggregated albumin (LyoMAA, Covidien, Neustadt, Germany).

\section{Comorbidity measurement}

To assess comorbidities, we used the Charlson Comorbidity Index (CCI) which is validated in older patients with the option to calculate an age adjusted index (Charlson Age Comorbidity Index, CACI) [24, 25] to predict mortality in a range of comorbid conditions. 19 comorbidity items were included and each condition was assigned a score of $1,2,3$ or 6 (see Table 3), depending on the risk of death associated with each one. The sum of these items (between 0 and 30) formed the final comorbidity index (CCI, CACI) that has been established as a predictor of patient outcome and mortality in different settings and larger populations including cancer patients [26]. The index disease, metastatic colorectal cancer, was excluded when calculating the index. Additional information was assessed regarding typical cardiovascular risk factors not included within the CCI (e.g. hypertension, hyperlipidemia, obesity).

All information on comorbidity was recorded at baseline.

\section{Statistical analysis}

SPSS 21.0 (IBM ${ }^{\circ}$, New York, USA) was used for the complete analysis set. Comorbidity items including the summary within the $\mathrm{CCI} / \mathrm{CACI}$, patient age and key characteristics of disease and treatment underwent a stepwise Cox regression analysis. All baseline variables were initially analyzed in a univariate Cox regression. Any variable scoring a $p$-value $<0.1$ was then included in a multivariate Cox proportional hazard model. Tables 3 and 4 give a summary of the main analysis with $p$-values, harzard ratios (HR) and 95\% confidence intervals (95\% CI). Statistical significance in the multivariate analysis was assumed for $p$-values $<0.05$. Visualization was achieved by Kaplan-Meier charts.

\section{Results}

Treatment outcome

A total of 732 procedures were performed in all patients, an overview is given in Table 1. All survival data were

Table 1 Overview on procedures and outcome

\begin{tabular}{|c|c|c|c|c|c|c|}
\hline & \multirow{3}{*}{$\begin{array}{l}\text { Patients } \\
n\end{array}$} & \multirow{3}{*}{$\begin{array}{l}\text { Procedures } \\
n\end{array}$} & \multicolumn{4}{|c|}{ Median overall survival (months) } \\
\hline & & & \multicolumn{2}{|l|}{ Patient age } & \multicolumn{2}{|c|}{ Comorbidity } \\
\hline & & & $\geq 70$ years & $<70$ years & $\mathrm{CCl} \geq 3$ & $\mathrm{CCl}<3$ \\
\hline RFA & 60 & 99 & $26.7 \mathrm{~m}$ & $24.3 \mathrm{~m}$ & $24.0 \mathrm{~m}$ & $26.2 \mathrm{~m}$ \\
\hline liver & 18 & 21 & & $(p=0.76)$ & & $(p=0.16)$ \\
\hline lung & 42 & 77 & & & & \\
\hline other & 1 & 1 & & & & \\
\hline HDR-BT & 192 & 491 & $19.1 \mathrm{~m}$ & $18.2 \mathrm{~m}$ & $16.4 \mathrm{~m}$ & 18.9 m \\
\hline liver & 176 & 422 & & $(p=0.83)$ & & $(p=0.43)$ \\
\hline lung & 29 & 52 & & & & \\
\hline lymph node & 9 & 9 & & & & \\
\hline other & 8 & 8 & & & & \\
\hline \multirow[t]{2}{*}{ Y90-RE } & 96 & 142 & $6.9 \mathrm{~m}$ & $6.5 \mathrm{~m}$ & $5.3 \mathrm{~m}$ & $6.9 \mathrm{~m}$ \\
\hline & & & & $(p=0.86)$ & & $(p=0.21)$ \\
\hline
\end{tabular}

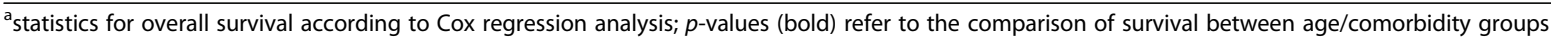


measured beginning with the first treatment at our institution.

\section{RFA patients}

Patients initially presenting with singular, small metastases $(<3 \mathrm{~cm})$ confined to lung $(n=42)$ or liver $(n=18)$ were treated by radiofrequency ablation yielding a median survival of 26.7 months and 24.4 months (including further local ablative treatments and/or systemic therapies in case of disease progression). A single RFA treatment was used for the ablation of a vertebral metastasis. 50 out of 60 patients (83\%) treated by RFA underwent multiple RFA sessions and/or further treatment by HDR-BT for recurrent metastases.

\section{CT-guided HDR brachytherapy patients}

Oligonodular and larger metastases were treated by HDR-BT. Patients with liver metastases eligible for HDR-BT at their first presentation in our department achieved a median survival of 18.1 months $(n=176)$. Initially applying HDR-BT to lung metastases, a median survival of 29.6 months was observed $(n=29)$. Lymphatic nodes and other infrequent localizations of metastases (e.g. adrenal glands, pancreas) were treated exclusively by HDR-BT with a corresponding median survival of 17.0 to 26.7 months. In patients with multiple tumor sites or disease progression during follow up, HDR-BT was repeated $(n=143)$ or Y90-RE performed $(n=28)$.

\section{Radioembolization patients}

Ninety- six patients with diffuse liver metastases underwent Y90-RE with a median survival of 6.7 months. 68 of these patients who had failed first and second line chemotherapy including variable treatment cycles with oxaliplatin, irinotecan and 5-fluorouracil demonstrated a significantly shorter median survival of 5.8 months in univariate and multivariate Cox regression analyses $(p<0.001)$. However, 19 salvage patients $(28 \%)$ undergoing Y90 radioembolization had a survival of at least 9 months with long-term survivors reaching a survival of nearly 30 months. All salvage patients treated by Y90-RE in this cohort represent a majority of patients in a dedicated prognostic analysis which can be reviewed for supplementary information [27].

\section{Impact of palliative chemotherapy after first interventional treatment}

A total of 120 patients (45\%) received further chemotherapy after the first local treatment. These patients demonstrated an improved survival of 22.0 vs. 16.1 months compared to patients without further systemic therapies $(p=0.009$; HR $0.71 ; 95 \%$ CI $0.55-0.92)$.
Table 2 Patient characteristics

\begin{tabular}{|c|c|c|}
\hline & $n$ & $\%$ \\
\hline All patients & 266 & 100.00 \\
\hline Male & 179 & 67.30 \\
\hline Female & 87 & 32.70 \\
\hline \multicolumn{3}{|l|}{ First diagnosis } \\
\hline Mean age (SD) in years & $63.0(+/-9.7)$ & \\
\hline \multicolumn{3}{|l|}{ Primary tumor } \\
\hline located in Colon (C18) & 151 & 56.77 \\
\hline Rectosigmoid junction (C19) & 18 & 6.77 \\
\hline Rectum (C20) & 98 & 36.84 \\
\hline $\mathrm{T} 1, \mathrm{~T} 2$ & 29 & 10.90 \\
\hline $\mathrm{T} 3, \mathrm{~T} 4$ & 227 & 85.30 \\
\hline T missing & 10 & 3.80 \\
\hline No & 74 & 27.80 \\
\hline $\mathrm{N} 1,2$ & 179 & 67.30 \\
\hline $\mathrm{N}$ status missing & 13 & 4.90 \\
\hline Synchronous metastases & 166 & 62.41 \\
\hline \multicolumn{3}{|l|}{ Prior treatment } \\
\hline Systemic chemotherapy & 248 & 93.23 \\
\hline Median lines of chemotherapy (range) & $2(0-8)$ & \\
\hline Radiochemotherapy & 30 & 11.28 \\
\hline Surgery for colorectal primary & 263 & 98.87 \\
\hline Radiation therapy for colorectal primary & 21 & 7.89 \\
\hline Surgery for liver metastases & 91 & 34.21 \\
\hline Other local treatment for liver metastases & 40 & 15.04 \\
\hline Surgery for lung metastases & 14 & 5.26 \\
\hline Surgery for other metastases & 20 & 7.52 \\
\hline Local therapy for other metastases & 5 & 1.88 \\
\hline \multicolumn{3}{|l|}{ First interventional treatment } \\
\hline Mean age (SD) in years & $66,5(+/-9.6)$ & \\
\hline Age $>70$ years & 89 & 33.5 \\
\hline Median Karnofsky index (range) in \% & $80(50-100)$ & \\
\hline Liver metastases & 251 & 96.99 \\
\hline Liver metastases only & 121 & 45.50 \\
\hline Liver involvement $>25 \%$ & 45 & 16.92 \\
\hline Lung involvement & 100 & 37.60 \\
\hline Other & 83 & 31.20 \\
\hline$\geq 2$ organ systems involved & 140 & 52.63 \\
\hline
\end{tabular}

\section{Outcome by patient characteristics}

Overall patient characteristics are outlined in Table 2. Survival in all patients accounted for 14 months, survival analysis was conducted using a stepwise Cox regression analysis. Nearly all patients suffered from liver metastases $(n=251)$. Patients with an initial positive $\mathrm{N}$ stage $(n$ 
$=179)$ and metachronous lymph node metastases $(n=$ 44) had a poorer prognosis (13.1 vs 17.0 months; 9.8 vs 16.1 months) after first interventional treatment in univariate analysis, yet multivariate regression analysis did not demonstrate a significant influence on overall survival ( $p=0.25$ and $p=0.17$; respectively).

Synchronous metastases at first diagnosis $(n=166)$ only had significant influence in univariate analysis $(p=0.036)$ but not in multivariate analysis $(p=0.90)$. Metachronous pulmonary metastases had no impact on survival $(p=0.55)$.

Systemic therapy options after initiation of interventional therapy were stratified by previous failure of either oxaliplatin or irinotecan based combined regimen (second line, $n=79$ ) or failure of both (third line, $n=160$ ). Patients without prior chemotherapy were classified to first line $(n=27)$, including patients with contraindications to systemic therapy. A median survival of 13.2 vs. 16.6 months was observed in patients receiving third line therapy compared to patients in earlier lines of therapy without prognostic influence in multivariate analysis $(p=0.30)$.

If third line patients were still eligible for local-ablative techniques (RFA and/or HDR-BT), the median survival reached 17.5 months $(n=114)$.

The complete multivariate analysis is demonstrated in Table 4.

\section{Age analysis}

Our cohort included 89 patients (33.5\%) 70 years or older. This patient group demonstrated no altered survival as compared to younger patients after first interventional therapy in a Cox regression analysis $(p=0.19$; HR 0.84; 95\% CI 0.64-1.10). Median survival in the subgroup of elder patients was 16.6 vs. 13.2 months as shown in Fig. 1.

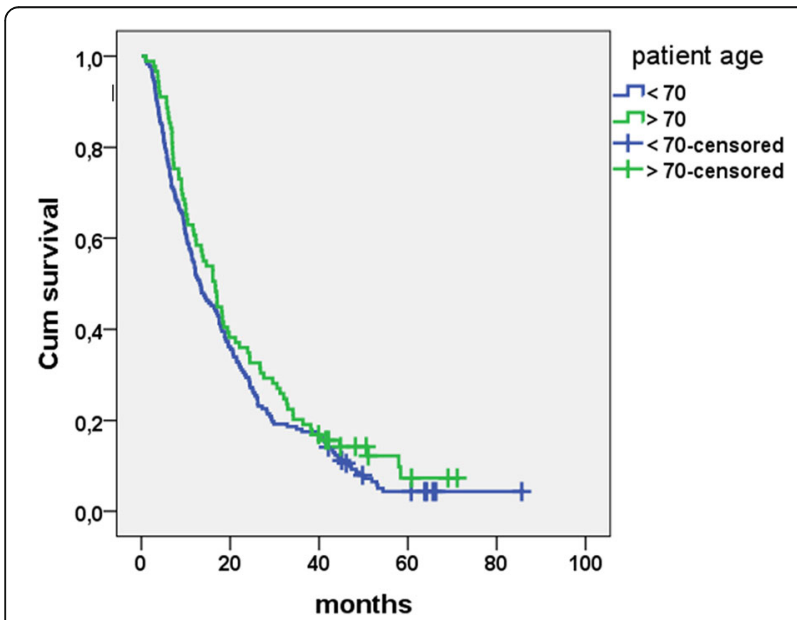

Fig. 1 Overall survival by age. Kaplan Meier estimation for overall survival after first treatment by age $<70$ (13.2 months; $n=177)$ and age $\geq 70$ (16.6 months; $n=89$ ), no statistical difference between groups ( $p=0.19$; Cox regression analysis)
In patients older than 70 years initial or additional lymphatic metastases were of no prognostic value $(p=0.11$; HR 1.24; $95 \%$ CI $0.95-1.61$ and $p=0.23$; HR 1.62; $95 \%$ CI $0.74-3.54)$, just as for heavily pretreated patients with at least three lines of systemic chemotherapy $(p=0.18$; HR 1.23; 95\% CI 0.91-1.67). Survival of elderly versus younger patients was similar regarding the first technique applied (RFA, HDR-BT or Y90-RE) in regression analysis, see Table 1 .

\section{Comorbidity analysis (CCl, $\mathrm{CACl})$}

With a sum of 3 points or more for the CCI, 43 patients (16.2\%) displayed severe comorbidities at baseline. These comorbidities were significantly more frequent in older patients $\geq 70$ years $(n=21 ; 23.6 \%)$ than in younger patients $<70$ years $(n=22$; $12.4 \%$; $p=0.023$; Chi-Square test). According to the age adjusted CACI, a total of 112 patients (42.1\%) were considered with severe comorbidities at first therapy. An overview of $\mathrm{CCI} / \mathrm{CACI}$ in the patient cohort is given in Table 3.

In a univariate Cox regression, both CCI or CACI ranging from 0 to 7 and $0-8$ had no significant impact on the patients prognosis $(p=0.82 ; p=0.86)$, respectively. Comparison of patients with severe comorbidities $(\mathrm{CCI} \geq 3)$ versus no or moderate comorbidities demonstrated no significant influence on overall survival either (18.8 months vs. 21.9 months; $p=0.41$; see Fig. 2). Regression analysis of all single items summarized in the index (see Table 3) revealed a significant influence of moderate or severe renal disease in 12 patients $(p=0.005)$. Two patients with gastric or duodenal ulcer died after 3.7 and 5.7 months, respectively $(p=0.006)$. Patients with chronic pulmonary disease $(n=29)$ had a lower hazard ratio $(p=0.006$; HR $0.61 ; 95$ CI $0.38-0.99$ ). No other comorbidity item had a considerable impact, despite 55 patients suffering from peripheral vascular disease and 36 patients with a history of myocardial infarction or coronary heart disease $(p=$ 0.81 and $p=0.38$ ). Multivariate regression analysis finally confirmed a statistical significant impact of moderate or severe renal disease in all patients $(p=0.005)$.

Apart from the conditions reflected in the CCI, 116 patients had been diagnosed with hypertension (43.6\%), 18 patients with obesity $(6.8 \%)$ and 20 with hyperlipidemia (7.5\%). None of these factors demonstrated a significant influence on survival as demonstrated in Table 4.

\section{Discussion}

\section{Interventional oncology in elderly patients}

Metastatic colorectal cancer continues to be a major therapeutic challenge especially in elderly patients as prevalence of comorbidity is considered to be more frequent compared to the background population [28]. The corresponding interaction between cancer and comorbidity, and whether comorbidity leads to cancer 
Table 3 Prevalence of comorbidities according to the Charlson Comorbidity index

\begin{tabular}{|c|c|c|c|c|c|}
\hline $\mathrm{CCl}^{\mathrm{a}}$ & condition & $n$ & $\%$ & $p$-value ${ }^{\circ}$ & HR $(95 \% \mathrm{Cl})$ \\
\hline \multirow[t]{10}{*}{1} & myocardial infarction, coronary artery disease & 36 & 13,5 & 0.38 & $0.85(0.58-1.23)$ \\
\hline & congestive heart failure & 15 & 5,6 & 0.62 & $0.87(0.51-1.50)$ \\
\hline & peripheral vascular disease & 55 & 20,7 & 0.81 & $0.96(0.71-1.31)$ \\
\hline & cerebrovascular disease & 13 & 4,9 & 0.58 & $0.85(0.48-1.52)$ \\
\hline & dementia & 0 & 0 & & \\
\hline & chronic pulmonary disease & 21 & 7,9 & 0.046 & $0.61(0.38-0.99)$ \\
\hline & connective tissue disorder & 2 & 0,8 & 0.93 & $0.94(0.23-3.78)$ \\
\hline & peptic ulcer disease & 2 & 0,8 & 0.006 & $7.40(1.80-30.50)$ \\
\hline & mild liver disease & 10 & 3,8 & 0.26 & $1.44(0.76-2.72)$ \\
\hline & diabetes without complications & 42 & 15,8 & 0.94 & $0.99(0.70-1.40)$ \\
\hline \multirow[t]{4}{*}{2} & diabetes with end-organ damage & 17 & 6,4 & 0.74 & $0.92(0.55-1.52)$ \\
\hline & hemiplegia & 1 & 0,4 & 0.70 & $1.48(0.21-10.61)$ \\
\hline & moderate/severe renal disease & 12 & 4,5 & 0.005 & $2.3(1.29-4.13)$ \\
\hline & any tumor without metastases (incl. Leukemia, lymphoma) & 34 & 12,8 & 0.89 & $1.03(0.71-1.50)$ \\
\hline 3 & moderate/severe liver disease & 3 & 1,1 & 0.33 & $1.77(0.57-5.55)$ \\
\hline \multirow[t]{2}{*}{6} & metastatic solid tumor (mCRC excluded) & 0 & 0 & & \\
\hline & AIDS & 0 & 0 & & \\
\hline 8 & AIDS and any tumor & 0 & 0 & & \\
\hline
\end{tabular}

age adjusted index $\mathrm{CACl}$ adds 1 point for each decade after 40 years

${ }^{\circ}$ statistics for overall survival according to univariate Cox regression, variables with univariate $p<0.1$ are processed in Table 4

diagnosis in earlier or later stages, is still object to ongoing discussions [29]. Furthermore, elderly and multimorbid patients are often not eligible for surgery or efficacious polychemotherapies [30].

In our group of metastatic CRC patients, about $62 \%$ had comorbidities according to the CCI. Adding conditions as hypertension, hyperlipidemia and obesity, 71\% of patients were suffering from comorbidities, which is

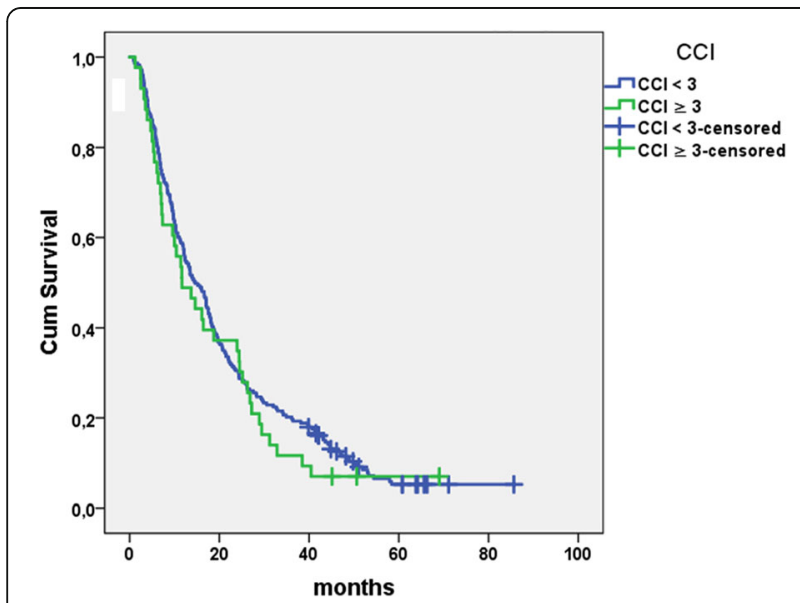

Fig. 2 Overall survival by CCI. Kaplan Meier estimation for overall survival after first treatment separated by Charlson Comorbidity Index $<3$ (21.9 months; $n=223$ ) and $\geq 3$ (18.1 months; $n=43$ ); no statistical difference between groups ( $p=0.41$; Cox regression analysis) far more frequent than in other studies applying the CCI reporting a prevalence between 32 and $41 \%$ in metastatic or non-metastatic CRC patients [31].

Median survival after RFA as first local treatment of liver metastases was 24.4 months in our patients, which is consistent with existing data ranging from 24 to 36 months [32].

As HDR-BT is usually applied in metastases exceeding the technical feasibility of RFA in size and number, thus adding an unfavorable prognosis bias, a corresponding median survival of 18.1 months was found in those patients. A retrospective analysis by Collettini et al. demonstrated a comparable median survival of 18 months after HDR-BT of colorectal liver metastases [33].

Most patients undergoing Y90-radioembolization had previously failed all accessible chemotherapies leading to a median survival of 5.8 months in this group. However, one quarter of these patients survived 9 or more months including a small group of long term survivors $>2$ years indicating that patient selection is of utmost importance in a salvage population [34]. This could be shown by our group in a previous study regarding the prognostic value of Karnofsky index, tumor load and tumor markers in patients undergoing Y90-radioembolization to help selecting appropriate patients [27].

When applying CCI and CACI to measure the prognostic impact of comorbidities in our patients, we did not observe a relation of higher index values with overall 
Table 4 Stepwise Cox regression analysis of key characteristics at baseline including CCI items with univariate $p<0.1$ (all items of CCl are shown in Table 3)

\begin{tabular}{|c|c|c|c|c|}
\hline Variable & Univariate $p$ & HR $(95 \% \mathrm{Cl})$ & Multivariate $p^{*}$ & $\mathrm{HR}(95 \% \mathrm{Cl})$ \\
\hline \multicolumn{5}{|l|}{$\mathrm{CCl}$ items $\mathrm{p}<0.1$} \\
\hline Chronic pulmonary disease & $0.046^{*}$ & $0.61(0.38-0.99)$ & 0.30 & $0.76(0.45-1.28)$ \\
\hline Peptic ulcer disease & $0.006^{*}$ & $7.40(1.80-30.50)$ & 0.17 & $2.75(0.65-11.69)$ \\
\hline Moderate/severe renal disease & $0.005^{*}$ & $2.3(1.29-4.13)$ & 0.005 & $2.46(1.32-4.57)$ \\
\hline \multicolumn{5}{|l|}{ Comorbidities not included in CCl } \\
\hline Hypertension & 0.54 & $0.93(0.72-1.20)$ & & \\
\hline Obesity & 0.32 & $0.77(0.47-1.28)$ & & \\
\hline Hyperlipidemia & 0.48 & $0.84(0.51-1.37)$ & & \\
\hline \multicolumn{5}{|l|}{ Patient and treatment characteristics } \\
\hline Age $>70$ years & 0.19 & $0.84(0.64-1.10)$ & & \\
\hline $\mathrm{CCl} \geq 3$ & 0.41 & $1.15(0.82-1.62)$ & & \\
\hline Positive N stage of primary & $0.004^{*}$ & $1.27(1.08-1.50)$ & 0.25 & $1.11(0.93-1.33)$ \\
\hline Synchronous metastases & $0.036^{*}$ & $1.36(1.02-1.81)$ & 0.90 & $0.98(0.71-1.35)$ \\
\hline Metachronous lymph node metastases & $0.032^{*}$ & $1.44(1.03-2.00)$ & 0.17 & $1.31(0.89-1.91)$ \\
\hline Metachronous pulmonary metastases & 0.55 & $1.09(0.83-1.43)$ & & \\
\hline 1st/2nd Line vs. 3rd Line treatment & $0.001^{*}$ & $0.83(0.77-0.90)$ & 0.30 & $0.89(0.72-1.1)$ \\
\hline Salvage treatment in Y90-RE & $0.001^{*}$ & $2.17(1.37-3.45)$ & $<0.001$ & $4.35(3.06-6.17)$ \\
\hline
\end{tabular}

*multivariate Cox regression analysis including all variables $p<0.1$ in univariate analysis

survival. It should be noted that about $42 \%$ of all patients had severe comobidities according to the age-adjusted index $(\mathrm{CACI} \geq 3)$. This finding supports the assumption that local ablative therapies such as RFA or HDR-BT, or a locoregional treatment such as Y90 radioembolization, can be safely applied in risk patients with a moderate toxicity profile or adverse event rate, respectively.

A similar relationship was seen recently by Jehn et al. in patients undergoing systemic therapy for $\mathrm{mCRC}$ as CCI and age showed no influence on survival [35]. In this population, adverse events were not found to be more frequent in elderly patients, although a significantly higher CCI was observed. Also response rates and survival were balanced irrespective of age and comorbidity. Further studies even discuss inferior outcome in younger patients, most probably caused by more aggressive tumor biology as compared to elder patients [36,37]. With regard to our patients treated by local therapies, we observed a similar trend potentially related to a more favorable tumor biology in the eldery.

\section{Implications}

Our study has demonstrated that older age or a higher rate of comorbidities with age (CCI and $\mathrm{CACI})$ do not influence survival in metastatic colorectal cancer when patients are selected for local or loco-regional ablation by RFA, HDR-BT or Y 90 radioembolization. A poorer survival was only seen in patients with moderate or severe renal impairment in our multivariate analysis. Renal disease in general is associated with a poor prognosis and has been reported to have a specifically negative impact on survival in different cancer populations [38].

\section{Limitations}

A possible source of error in our analysis may result from data being derived from discharge diagnoses or follow up documentation in our own medical hospital records. Conditions treated by the general practitioner or subsequently in other hospitals may not have been completely represented in our data as a result of the studies retrospective nature. Furthermore, our sample is not necessarily representative for all $\mathrm{mCRC}$ patients with a comparatively high frequency of comorbidities in our cohort as compared to other studies. However, we hypothesize that these finding exclude a positive selection in our cohort.

\section{Conclusion}

The tool box of image guided treatments proved to be safe and applicable even in patients of higher age or patients presenting with comorbidities. Our study results support offering ablative treatments to metastatic colorectal cancer patients even at advanced age or high Charlson indices.

\section{Abbreviations}

CACl: Charlson Age Comorbidity Index; CCl: Charlson Comorbidity Index; CT: Computed tomography; ESMO: European Society for Medical Oncology; HDR-BT: High-dose rate brachytherapy; mCRC: metastatic colorectal cancer; MRI: magnetic resonance imaging; RFA: Radiofrequency ablation; Y90RE: Y90-radioembolization 


\section{Acknowledgements}

Ricarda Seidensticker and Robert Damm contributed equally and share the first authorship.

\section{Funding}

The authors state that this work has not received any funding.

\section{Availability of data and materials}

All relevant data regarding the study conclusion are displayed in the publication. Raw data used and/or analysed during the study are available from the corresponding author on reasonable request.

\section{Authors' contributions}

RS and RD participated in the design of the study, carried out data analysis and statistical work, drafted the manuscript. JE helped in the organization of the study and performed data acquisition and interpretation. MS participated in the design of the study and helped to revise the manuscript. $\mathrm{KM}$ and PH participated in the data acquisition and data interpretation. MP and HA participated in the design of the study and performed data interpretation. JR participated in the design of the study, helped drafting the manuscript and carried out the final revision. All authors have given final approval for the manuscript and takes public responsibility.

\section{Ethics approval and consent to participate}

The study was conducted in accordance with the Declaration of Helsinki. All patients included were treated at a single institution, retrospective data collection and analysis was approved by the local ethics committee (Ottovon-Guericke University Magdeburg). All patients gave written informed consent for the collection of their medical data for scientific purposes.

\section{Consent for publication}

No personal information is included in the publication, thus no dedicated approval was required.

\section{Competing interests}

$R S, M S, K M, H A, M P, J R$ have received lecture fees and/or travel grants from Sirtex Medical Europe.

\section{Publisher's Note}

Springer Nature remains neutral with regard to jurisdictional claims in published maps and institutional affiliations.

\section{Author details}

'Department of Radiology, Ludwig-Maximilians-University Munich, Munich, Germany. ${ }^{2}$ Department of Radiology and Nuclear Medicine, Otto-von-Guericke-University Magdeburg, Leipziger Str. 44, 39120 Magdeburg, Germany. ${ }^{3}$ Diagnostic and Treatment Center Frankfurter Tor, Berlin, Germany. ${ }^{4}$ Department of Radiation Oncology,

Otto-von-Guericke-University Magdeburg, Berlin, Germany. ${ }^{5}$ Department of Nuclear Medicine, Charite, Berlin, Germany. ${ }^{6}$ Deutsche Akademie für Mikrotherapie e.V, Magdeburg, Germany.

\section{Received: 26 June 2018 Accepted: 30 August 2018}

Published online: 10 September 2018

\section{References}

1. Balducci L. Geriatric oncology: challenges for the new century. Eur J Cancer. 2000;36(14):1741-54.

2. Aapro MS, Kohne $\mathrm{CH}$, Cohen HJ, Extermann M. Never too old? Age should not be a barrier to enrollment in cancer clinical trials. Oncologist. 2005;10(3): 198-204.

3. Lewis JH, Kilgore ML, Goldman DP, Trimble EL, Kaplan R, Montello MJ, Housman MG, Escarce JJ. Participation of patients 65 years of age or older in cancer clinical trials. J Clin Oncol. 2003:21(7):1383-9.

4. Talarico L, Chen G, Pazdur R. Enrollment of elderly patients in clinical trials for cancer drug registration: a 7-year experience by the US Food and Drug Administration. J Clin Oncol. 2004;22(22):4626-31.

5. Basdanis G, Papadopoulos VN, Michalopoulos A, Fahantidis E, Apostolidis S, Berovalis P, Zatagias A, Karamanlis E. Colorectal cancer in patients over 70 years of age: determinants of outcome. Tech Coloproctol. 2004;8(Suppl 1): s112-5.
6. Etzioni DA, El-Khoueiry AB, Beart RWJ. Rates and predictors of chemotherapy use for stage III colon cancer: a systematic review. Cancer. 2008;113(12):3279-89.

7. Keating $\mathrm{NL}$, Landrum $\mathrm{MB}$, Klabunde $\mathrm{CN}$, Fletcher $\mathrm{RH}$, Rogers $\mathrm{SO}$, Doucette WR, Tisnado D, Clauser S, Kahn KL. Adjuvant chemotherapy for stage III colon cancer: do physicians agree about the importance of patient age and comorbidity? J Clin Nutr. 2008;26(15):2532-7.

8. Daniele B, Croitoru A, Papandreou C, Bronowicki JP, Mathurin P, Serejo F, Stal P, Turnes J, Ratziu V, Bodoky G. Impact of sorafenib dosing on outcome from the European patient subset of the GIDEON study. Future Oncol. 2015;11(18):2553-62.

9. Nakayama G, Tanaka C, Uehara K, Mashita N, Hayashi N, Kobayashi D, Kanda M, Yamada S, Fujii T, Sugimoto $H$, et al. The impact of dose/time modification in irinotecan- and oxaliplatin-based chemotherapies on outcomes in metastatic colorectal cancer. Cancer Chemother Pharmacol. 2014:73(4):847-55.

10. Venderbosch S, Doornebal J, Teerenstra S, Lemmens W, Punt CJ, Koopman M. Outcome of first line systemic treatment in elderly compared to younger patients with metastatic colorectal cancer: a retrospective analysis of the CAIRO and CAIRO2 studies of the Dutch colorectal Cancer group (DCCG). Acta Oncol. 2012;51(7):831-9.

11. de Baere T, Tselikas L, Yevich S, Boige V, Deschamps F, Ducreux M, Goere D, Nguyen F, Malka D. The role of image-guided therapy in the management of colorectal cancer metastatic disease. Eur J Cancer. 2017:75:231-42.

12. Kennedy A, Cohn M, Coldwell DM, Drooz A, Ehrenwald E, Kaiser A, Nutting CW, Rose SC, Wang EA, Savin MA. Updated survival outcomes and analysis of long-term survivors from the MORE study on safety and efficacy of radioembolization in patients with unresectable colorectal cancer liver metastases. J Gastrointest Oncol. 2017;8(4):614-24.

13. Sangha BS, Nimeiri H, Hickey R, Salem R, Lewandowski RJ. Radioembolization as a treatment strategy for metastatic colorectal Cancer to the liver: what can we learn from the SIRFLOX trial? Curr Treat Options in Oncol. 2016;17(6):26.

14. Van Cutsem E, Cervantes A, Adam R, Sobrero A, Van Krieken JH, Aderka D, Aranda Aguilar E, Bardelli A, Benson A, Bodoky G, et al. ESMO consensus guidelines for the management of patients with metastatic colorectal cancer. Ann Oncol. 2016;27(8):1386-422.

15. Buscarini E, Savoia A, Brambilla G, Menozzi F, Reduzzi L, Strobel D, Hansler J, Buscarini L, Gaiti L, Zambelli A. Radiofrequency thermal ablation of liver tumors. Eur Radiol. 2005;15(5):884-94.

16. Lin ZY, Li GL, Chen J, Chen ZW, Chen YP, Lin SZ. Effect of heat sink on the recurrence of small malignant hepatic tumors after radiofrequency ablation. J Cancer Res Ther. 2016;12(Supplement):C153-8.

17. Peters N, Wieners G, Pech M, Hengst S, Ruhl R, Streitparth F, Lopez Hanninen E, Felix R, Wust P, Ricke J. CT-quided interstitial brachytherapy of primary and secondary lung malignancies: results of a prospective phase II trial. Strahlentherapie und Onkologie : Organ der Deutschen Rontgengesellschaft [et al]. 2008;184(6):296-301.

18. Collettini F, Singh A, Schnapauff D, Powerski MJ, Denecke T, Wust P, Hamm B, Gebauer B. Computed-tomography-guided high-dose-rate brachytherapy (CT-HDRBT) ablation of metastases adjacent to the liver hilum. Eur J Radiol. 2013;82(10):e509-14.

19. Ricke J, Wust P, Wieners G, Beck A, Cho CH, Seidensticker M, Pech M, Werk M, Rosner C, Hanninen EL, et al. Liver malignancies: CT-guided interstitial brachytherapy in patients with unfavorable lesions for thermal ablation. J Vasc Interv Radiol. 2004;15(11):1279-86.

20. Wieners G, Pech M, Rudzinska M, Lehmkuhl L, Wlodarczyk W, Miersch A, Hengst S, Felix R, Wust P, Ricke J. CT-guided interstitial brachytherapy in the local treatment of extrahepatic, extrapulmonary secondary malignancies. Eur Radiol. 2006;16(11):2586-93.

21. Ricke J, Mohnike K, Pech M, Seidensticker M, Ruhl R, Wieners G, Gaffke G, Kropf S, Felix R, Wust P. Local response and impact on survival after local ablation of liver metastases from colorectal carcinoma by computed tomography-guided high-dose-rate brachytherapy. Int J Radiat Oncol Biol Phys. 2010;78(2):479-85.

22. Jakobs TF, Hoffmann RT, Dehm K, Trumm C, Stemmler HJ, Tatsch K, La Fougere C, Murthy R, Helmberger TK, Reiser MF. Hepatic yttrium-90 radioembolization of chemotherapy-refractory colorectal cancer liver metastases. J Vasc Interv Radiol. 2008;19(8):1187-95.

23. Kennedy AS, Coldwell D, Nutting C, Murthy R, Wertman DE Jr, Loehr SP, Overton C, Meranze S, Niedzwiecki J, Sailer S. Resin 90Y-microsphere 
brachytherapy for unresectable colorectal liver metastases: modern USA experience. Int J Radiat Oncol Biol Phys. 2006;65(2):412-25.

24. Charlson M, Szatrowski TP, Peterson J, Gold J. Validation of a combined comorbidity index. J Clin Epidemiol. 1994;47(11):1245-51.

25. Charlson ME, Pompei P, Ales KL, Mackenzie CR. A new method of classifying prognostic comorbidity in longitudinal studies: development and validation. J Chronic Dis. 1987;40(5):373-83.

26. Ouellette JR, Small DG, Termuhlen PM. Evaluation of Charlson-age comorbidity index as predictor of morbidity and mortality in patients with colorectal carcinoma. J Gastrointest Surg. 2004;8(8):1061-7.

27. Damm R, Seidensticker R, Ulrich G, Breier L, Steffen IG, Seidensticker M, Garlipp B, Mohnike K, Pech M, Amthauer H, et al. Y90 Radioembolization in chemo-refractory metastastic, liver dominant colorectal cancer patients: outcome assessment applying a predictive scoring system. BMC Cancer. 2016;16:509.

28. Jorgensen TL, Hallas J, Friis S, Herrstedt J. Comorbidity in elderly cancer patients in relation to overall and cancer-specific mortality. Br J Cancer. 2012;106(7):1353-60.

29. Sogaard M, Thomsen RW, Bossen KS, Sorensen HT, Norgaard M. The impact of comorbidity on cancer survival: a review. Clin Epidemiol. 2013;5(Suppl 1):3-29.

30. Lund CM, Vistisen KK, Dehlendorff C, Ronholt F, Johansen JS, Nielsen DL The effect of geriatric intervention in frail elderly patients receiving chemotherapy for colorectal cancer: a randomized trial (GERICO). BMC Cancer. 2017;17(1):448.

31. Ostenfeld EB, Norgaard M, Thomsen RW, Iversen LH, Jacobsen JB, Sogaard M. Comorbidity and survival of Danish patients with colon and rectal cancer from 2000-2011: a population-based cohort study. Clin Epidemiol. 2013; 5(Suppl 1):65-74.

32. Solbiati L, Livraghi T, Goldberg SN, lerace T, Meloni F, Dellanoce M, Cova L, Halpern EF, Gazelle GS. Percutaneous radio-frequency ablation of hepatic metastases from colorectal cancer: long-term results in 117 patients. Radiology. 2001;221(1):159-66.

33. Collettini F, Lutter A, Schnapauff D, Hildebrandt B, Puhl G, Denecke T, Wust $P$, Gebauer B. Unresectable colorectal liver metastases: percutaneous ablation using CT-guided high-dose-rate brachytherapy (CT-HDBRT). Rofo. 2014;186(6):606-12.

34. Seidensticker R, Denecke T, Kraus P, Seidensticker M, Mohnike K, Fahlke J, Kettner E, Hildebrandt B, Dudeck O, Pech M, et al. Matched-pair comparison of radioembolization plus best supportive care versus best supportive care alone for chemotherapy refractory liver-dominant colorectal metastases. Cardiovasc Intervent Radiol. 2012;35(5):1066-73.

35. Jehn CF, Boning L, Kroning H, Pezzutto A, Luftner D. Influence of comorbidity, age and performance status on treatment efficacy and safety of cetuximab plus irinotecan in irinotecan-refractory elderly patients with metastatic colorectal cancer. Eur J Cancer. 2014;50(7):1269-75.

36. Bakogeorgos M, Mountzios G, Kotsantis G, Economopoulou P, Fytrakis N, Kentepozidis N. Chemotherapy compliance, tolerance and efficacy in elderly and non-elderly patients with metastatic colorectal cancer: a single institution comparative study. J BUON. 2013;18(3):629-34.

37. Steele SR, Park GE, Johnson EK, Martin MJ, Stojadinovic A, Maykel JA, Causey $\mathrm{MW}$. The impact of age on colorectal cancer incidence, treatment, and outcomes in an equal-access health care system. Dis Colon Rectum. 2014; 57(3):303-10.

38. Sarfati D, Gurney J, Lim BT, Bagheri N, Simpson A, Koea J, Dennett E. Identifying important comorbidity among cancer populations using administrative data: prevalence and impact on survival. Asia Pac J Clin Oncol. 2013;12(1):e47-56.

Ready to submit your research? Choose BMC and benefit from:
- fast, convenient online submission
- thorough peer review by experienced researchers in your field
- rapid publication on acceptance
- support for research data, including large and complex data types
- gold Open Access which fosters wider collaboration and increased citations
- maximum visibility for your research: over 100M website views per year
At BMC, research is always in progress.
Learn more biomedcentral.com/submissions

